ББК 67.400.6

\title{
ФОРМЫ И МЕТОДЫ АДМИНИСТРАТИВНО-ПРАВОВОГО РЕГУЛИРОВАНИЯ В СОЦИАЛЬНО-ЭКОНОМИЧЕСКОЙ СФЕРЕ
}

\author{
(C) 2020 Щукина Татьяна Владимировна \\ доктор юридических наук, доцент, ведущий научный сотрудник \\ Институт государства и права Российской академии наук, Россия, Москва \\ E-mail: shukina-tv@mail.ru
}

Предметом настоящей статьи выступает исследование новых форм и методов реализации государственного управления в социально-экономической сфере, включая рассмотрение современного правового регулирования. Тема статьи отражает вопросы трансформации форм и методов государственного управления в социально-экономической сфере с точки зрения формирования инновационной инфраструктуры стратегического развития в Российской Федерации. Целью настоящей статьи являются выявление новой системы форм и методов государственного управления в социально-экономической сфере на современном этапе управления, места и роли государства в этом процессе. Методологию данной работы составили сравнительный, формально-юридический, аналитический методы. Результаты работы - это формулирование особенностей методов и форм управления в социально-экономической сфере. Область применения результатов работы включает в себя систему публичного управления.

Ключевые слова: государственное управление в социально-экономической сфере, формы и методы управления.

Государственное управление неразрывно связано с формированием и развитием правового института права собственности, а также с изменением сущности объектов государственного управления. Без рассмотрения данного аспекта государственного управления со стороны государства невозможно определить основные тенденции модернизации форм и методов государственного управляющего воздействия. Отсутствие права частной собственности в советском государстве определяло специфику структуры, компетенции и видов органов исполнительной власти в сфере управления народным хозяйством.

В структуре органа государственного управления выделялись отраслевые отделы (управления), которые предназначались для руководства конкретной отраслью хозяйственного или культурного строительства как непосредственно, так и через подразделения аппарата Совета народных депутатов (законодательный орган), а также подведомственными предприятиями, учреждениями и организациями [1]. В советский период отраслевой аппарат управления местного органа государственной власти охватывал следующие отрасли управления [2]: местной промышленностью, сельским, водным и лесным хозяйством, капитальным строительством, газовым хозяйством, профессионально-техническим образованием, культурой, промышленностью продовольственных товаров, коммунальным хозяйством, бытовым обслуживанием, строительством и ремонтом автомобильных дорог, аптечным хозяйством, здравоохранением, народным образованием, социальным обеспечением, строительством и архитектурой.

В зависимости от особенностей экономических связей в регионе существовали местные органы государственного управления и их структурные подразделения в таких сферах управления, как [3]: автомобильного транспорта, промышленности строительных материалов и строительных деталей, общественного питания, высотных домов и гостиниц, городского оформления и рекламы, лесопаркового хозяйства, металлообрабатывающей промышленности и метрополитена. Помимо вышеуказанных местных органов государственного управления и их структурных подразделений осуществляли деятельность на краевом и областном уровнях организации, как БТИ, государственный арбитраж, ремонтно-строительные конторы.

В свою очередь, система местных органов государственного управления (области, края, 
города, сельского поселения) в целом включала в себя [4] исполнительные органы местных Советов, органы центра на местах; администрации предприятий и социально-культурных учреждений, деятельность которых была связана с обслуживанием населения, а также с осуществлением на соответствующих территориях функций инструктивно-методического, планово-регулирующего или контрольного характера.

Из вышеуказанной структуры системы местных органов государственного управления усматривается сочетание непосредственного наличия органов, осуществляющих публичное управление, и организаций, не обладающих целенаправленными государственными полномочиями по управлению территорией. И в тоже время, предприятий и учреждений, наделенных хозяйственными и социально-культурными функциями, носящими частично публичный характер. В современном понимании - публичными юридическими лицами, реализующими публичный интерес в хозяйственной (предпринимательской) и социально-культурной сфере территории (региона). Кроме того, данная система предполагала и видовое разнообразие местных органов государственного управления. Относительно компетенции местных органов государственного управления необходимо отметить, что она носила в большей степени отраслевой характер, соответствующий имеющимся принципам и правилам правового регулирования.

Проанализировав направления и виды сфер, отраслей государственного управления, регулирование которых охватывалось органами государственной власти, следует отметить, что компетенция органов управления в то время была очень широкой и разнообразной. Как собственно и наименования структурных подразделений органов государственного управления.

В настоящее время происходит расширение форм и методологии государственного управления. Это обусловлено структурными и содержательными изменениями объектов государственного управления. Укрепление позиций права собственности и его абсолютная правовая защита обеспечили формирование новой системы и структуры органов исполнительной власти, а также новые форматы их взаимодействия с подчиненными организациями и организациями негосударственного сектора. «Методология административно-правового регулирования пополняется за счет имплементации в нормативные правовые акты экономических, политологических методов, методов логистики. Кроме того, для административно-правового регулирования стало присуще более широкое использование принципов и методов частно-правового регулирования (автономность воли сторон, свобода заключения договора и т.п.), что определяет специфику статуса частно-публичного субъекта управления, создание новых форм и видов публичного управления» [5].

Большое значение придается в настоящее время методу проектного управления в системе публичного управления. По мнению ученых, «управление проектами в органах государственной власти отличается от управления проектами в предпринимательской деятельности. Оно носит жесткий правовой характер, подотчетно вышестоящим органам исполнительной власти, финансируется за счет бюджетных ресурсов; подлежит общественному контролю и публичной отчетности. И относительно содержания самих проектов, то они масштабны, многогранны, направлены на достижение социального эффекта прежде, чем будет получена выгода от привлечения в него инвестиций. Цели государственных проектов амбициозны и носят долгосрочный характер» [6].

Формы и методы административноправового регулирования стали неразрывно связаны с проводимой государственной политикой. Коснемся статьи 114 пункта «в» Конституции Российской Федерации, где предусматриваются социально ориентированные полномочия Правительства Российской Федерации, заключающиеся в обеспечении проведения в Российской Федерации единой государственной политики в области культуры, науки, образования, здравоохранения, социального обеспечения, поддержки, укрепления и защиты семьи, сохранения традиционных семейных ценностей, а также в области охраны окружающей среды. Обеспечение единой государственной политики осуществляется при помощи обновленных методов и форм административно-правового регулирования. Это связано со следующими факторами:

а) объединение усилий органов государственной власти и негосударственного сектора по реализации партнерского воздействия государства на социально значимые общественные отношения, как на федеральном уровне, так и на 
уровне субъектов Российской Федерации;

б) расширение круга правовых отношений, охватываемых полномочиями Правительства Российской Федерации, характеризующегося высокой общественной значимостью для государства.

Понятие государственной политики в юридической литературе неоднозначно и трактуется учеными по-разному. Например, в судебной практике государственная социальная политика определяется, исходя из статуса Российской Федерации как социального государства и соответствующих положений Конституции РФ. «Российская Федерация - это социальное государство, политика которого направлена на создание условий, обеспечивающих достойную жизнь и свободное развитие человека. В Российской Федерации охраняется труд и здоровье людей, устанавливается гарантированный минимальный размер оплаты труда, обеспечивается государственная поддержка семьи, материнства, отцовства и детства, инвалидов и пожилых граждан, развивается система социальных служб, устанавливаются государственные пенсии, пособия и иные гарантии социальной защиты (статья 7 Конституции Российской Федерации)».

Подобное видение государственной политики представлено в обзоре судебной практики Верховного Суда Российской Федерации № 2 (2020), утвержденном Президиумом Верховного Суда РФ 22 июля 2020 года, поэтому выработка государственной политики Правительством РФ основывается на федеральных законодательных актах и нормативных правовых актах Президента РФ стратегического характера. Кроме того, является ключевым направлением деятельности Правительства Российской Федерации в социальной сфере.

Необходимо отметить некоторые особенности правового регулирования современной государственной политики. Основы правового регулирования государственной политики базируются на положениях федерального закона от 28 июня 2014 г. № 172-Ф3 «О стратегическом планировании в Российской Федерации» и стратегических указов Президента Российской Федерации. Согласно данному федеральному закону подобное планирование осуществляется на федеральном уровне, уровне субъектов Российской Федерации и уровне муниципальных образований. Закон устанавливает правовые основы стратегического планирования в Российской
Федерации, координации государственного и муниципального стратегического управления и бюджетной политики, полномочия федеральных органов государственной власти, органов государственной власти субъектов Российской Федерации, органов местного самоуправления и порядок их взаимодействия с общественными, научными и иными организациями в сфере стратегического планирования.

Указы Президента Российской Федерации, содержащие поручения по реализации целей и мероприятий социальной политики, носят организационно-исполнительский характер и содержат поручения, которые Правительство Российской Федерации должно выполнить в порядке своей исполнительно-административной, управленческой деятельности (решение Верховного Суда Российской Федерации от 14 марта 2018 г. № АКПИ18-4). К таким указам относятся:

- указ Президента Российской Федерации от 7 мая 2018 г. № 204 «О национальных целях и стратегических задачах развития Российской Федерации на период до 2024 года»;

- указ Президента Российской Федерации от 21 июля 2020 г. № 474 «О национальных целях развития Российской Федерации на период до 2030 года».

Во исполнение указа Президента Российской Федерации от 21 июля 2020 г. № 474 «О национальных целях развития Российской Федерации на период до 2030 года» разработан Единый план по достижению национальных целей развития Российской Федерации на период до 2024 года и Основные направления деятельности Правительства Российской Федерации на период до 2024 года. Инструментами реализации ОНДП являются государственные программы Российской Федерации, наиболее значительные направления, реализации которых выделены в национальные проекты (программы). НДП определяют систему приоритетов и целевых ориентиров деятельности Правительства Российской Федерации на среднесрочную перспективу, устанавливают механизмы обеспечения прорывного научно-технологического и социально-экономического развития России в соответствии с компетенцией Правительства Российской Федерации.

В свою очередь, государственные программы и национальные проекты (программы) представляют собой комплексы мероприятий по достижению целевых показателей, структу- 
рированные по этапам, срокам и ответственным исполнителям. Принципы разработки и реализации государственных программ были закреплены и в распоряжении Правительства Российской Федерации № 1101-р от 30 июня 2010 года, и в Методических указаниях по разработке и реализации государственных программ Российской Федерации. Под государственной программой понимается документ стратегического планирования, содержащий комплекс планируемых мероприятий, взаимоувязанных по задачам, срокам осуществления, исполнителям и ресурсам, и инструментов государственной политики, обеспечивающих в рамках реализации ключевых государственных функций достижение приоритетов и целей государственной политики в сфере социально-экономического развития и обеспечения национальной безопасности Российской Федерации. Государственные программы представляют собой определенную систему.

«При этом система управления национальными проектами (программами) отвечает принципам проектного управления: в национальных проектах (программах) обозначены конкретные механизмы и инструменты достижения целевых показателей, объемы и источники их финансирования. Согласно Порядку разработки, реализации и оценки эффективности государственных программ Российской Федерации, утв. постановлением Правительства Российской Федерации от 2 августа 2010 г. № 588 государственная программа включает в себя федеральные целевые программы и подпрограммы, содержащие, в том числе, ведомственные целевые программы и основные мероприятия органов государственной власти. Подпрограммы направлены на достижение целей и решение задач в рамках государственной программы. Перечень государственных программ утверждается Правительством Российской Федерации» [7].

«Ведомственная целевая программа - это нормативный правовой акт, направленный на осуществление федеральными органами исполнительной власти, иными федеральными государственными органами и организациями, являющимися главными распорядителями бюджетных средств:

- государственной политики в установленных сферах деятельности;

- на обеспечение целей государственных программ РФ;

- на решение конкретной задачи подпро- граммы государственной программы;

- решение задач федерального органа исполнительной власти (федерального государственного органа или организации), если ведомственная целевая программа реализуется в рамках не программных направлений деятельности;

- на повышение результативности расходов федерального бюджета (постановление Правительства Российской Федерации от 19 апреля 2005 года № 239 «Об утверждении Положения о разработке, утверждении и реализации ведомственных целевых программ»)» [8].

Особый порядок разработки, реализации и оценки эффективности государственных программ распространяется на программу вооружения и программы Российской Федерации: «Развитие здравоохранения», «Развитие образования», «Обеспечение доступным и комфортным жильем и коммунальными услугами граждан Российской Федерации», «Развитие транспортной системы», «Государственная программа развития сельского хозяйства и регулирования рынков сельскохозяйственной продукции, сырья и продовольствия на 2013-2020 годы». Ранее эти программы реализовывались в рамках федеральных целевых программ, с 2018 года они погружены в содержание пилотных государственных программ.

«Рамочные требования к национальным проектам закреплены в указе Президента Российской Федерации «О национальных целях и стратегических задачах развития Российской Федерации на период до 2024 года» от 7 мая 2018 года № 204. Они заключаются в том, что национальные проекты должны способствовать эффективному достижению национальных целей и стратегических направлений развития Российской Федерации. Осуществление национальных проектов и программ предполагает достижение к 2024-2030 годам достижение установленных в указах Президента Российской Федерации национальных целей развития Российской Федерации. Национальные проекты реализуются с 2018 года по направлениям стратегического развития Российской Федерации» [9]. Национальные цели развития носят «межпрограммный» («межпроектный») характер: достижение ни одной из национальных целей не может быть обеспечено в рамках лишь одной государственной программы и (или) национального проекта (программы). Кроме того, национальные цели 
развития тесно взаимосвязаны между собой. Достижение одних целей находится в прямой зависимости от достижения других.

Рассмотрим некоторые особенности форм и методов административно-правового регулирования в сфере науки и образования. Основополагающим законодательным актом в сфере правового регулирования образования и науки является федеральный закон от 29 декабря 2012 г. № 273-Ф3 «Об образовании в Российской Федерации». Государственная политика в сфере образования основывается, в частности, на следующих принципах:

а) признание приоритетности образования;

б) обеспечение права каждого человека на образования, недопустимость дискриминации в сфере образования;

в) гуманистический характер образования, приоритет жизни и здоровья человека, прав и свобод личности, свободного развития личности, воспитание взаимоуважения, трудолюбия, гражданственности, патриотизма, ответственности, правовой культуры, бережного отношения к природе и окружающей среде, рационального природопользования и др.

В Российской Федерации гарантируется право каждого человека на образование. В нашем государстве гарантируются общедоступность и бесплатность в соответствии с федеральными государственными образовательными стандартами дошкольного, начального общего, основного общего и среднего общего образования, среднего профессионального образования, а также на конкурсной основе бесплатность высшего образования, если образование данного уровня гражданин получает впервые. Система образования создает условия для непрерывного образования посредством реализации основных образовательных программ и различных дополнительных образовательных программ, предоставления возможности одновременного освоения нескольких образовательных программ, а также учета имеющихся образования, квалификации, опыта практической деятельности при получении образование.

Проектным стратегическим документом, регламентирующим государственную политику в сфере образования, является постановление Правительства Российской Федерации от 26 декабря 2017 г. № 1642 «Об утверждении государственной программы Российской Федерации «Развитие образования» (с изм. от 16 июля
2020 г. № 1063). Федеральная государственная программа «Развитие образования» рассчитана на 2018-2025 годы и предусматривает проектное управление. Она включает в себя четыре направления (подпрограмм), которые в свою очередь состоят из одиннадцати федеральных проектов и девяти ведомственных целевых программ. Это - четыре направления: 1) «Развитие среднего профессионального и дополнительного профессионального образования», 2) «Развитие дошкольного и общего образования», 3) «Развитие дополнительного образования детей и реализация мероприятий молодежной политики», 4) «Совершенствование управления системой образования». Федеральные проекты:

- федеральный проект «Молодые профессионалы (Повышение конкурентоспособности профессионального образования)»;

- федеральный проект «Современная школа»;

- федеральный проект «Успех каждого ребенка»;

- федеральный проект «Поддержка семей, имеющих детей»;

- федеральный проект «Цифровая образовательная среда»;

- федеральный проект «Учитель будущего»;

- федеральный проект «Содействие занятости женщин - создание условий дошкольного образования для детей в возрасте до трех лет»;

- федеральный проект «Кадры для цифровой экономики»;

- федеральный проект «Социальная активность»;

- федеральный проект «Социальные лифты для каждого»;

- федеральный проект «Цифровая культуpa».

В качестве результатов исполнения мероприятий по федеральным проектам установлено, например: вхождение Российской Федерации в число 10 ведущих стран мира по качеству общего образования. Предлагается это реализовать посредством обновления содержания и технологий преподавания общеобразовательных программ, вовлечения всех участников системы образования (обучающиеся, педагоги, родители (законные представители), работодатели и представители общественных объединений) в развитие системы общего образования, а также за счет обновления материально-технической базы за 2019-2024 годы (федеральный проект 
«Современная школа»).

Другим стратегическим документом, касающимся модернизации российского образования, выступает национальный проект «Образование». Его цели - это обеспечение глобальной конкурентоспособности российского образования и вхождение Российской Федерации в число 10 ведущих стран мира по качеству общего образования место Российской Федерации в мире по присутствию университетов в ТОП-500 глобальных рейтингов университетов. Национальный проект «Образование» включает в себя десять федеральных проектов:

- Современная школа;

- Успех каждого ребенка;

- Поддержка семей, имеющих детей;

- Цифровая образовательная среда;

- Молодые профессионалы (Повышение конкурентоспособности профессионального образования);

- Новые возможности для каждого;

- Социальная активность;

- Экспорт образования;

- Социальные лифты для каждого.

В области науки стратегическими документами государственной политики являются:

- Стратегия научно-технологического развития Российской Федерации, утвержденная указом Президента Российской Федерации от 1 декабря 2016 г. № 642;

- паспорт национального проекта «Наука», утв. президиумом Совета при Президенте Российской Федерации по стратегическому развитию и национальным проектам (протокол от 24 декабря 2018 г. № 16). Данный национальный проект содержит три масштабных федеральных проекта: 1) федеральный проект «Развитие научной и научно-производственной кооперации», 2) федеральный проект «Развитие передовой инфраструктуры для проведения исследований и разработок в Российской
Федерации», 3) федеральный проект «Развитие кадрового потенциала в сфере исследований и разработок». Основными тремя целевыми показателями национального проекта обозначены: 1) обеспечение присутствия Российской Федерации в числе пяти ведущих стран мира, осуществляющих научные исследования и разработки в областях, определяемых приоритетами научнотехнологического развития; 2) обеспечение привлекательности работы в Российской Федерации для российских и зарубежных ведущих ученых и молодых перспективных исследователей; 3) опережающее увеличение внутренних затрат на научные исследования и разработки за счет всех источников по сравнению с ростом валового внутреннего продукта страны.

- Единый план по достижению национальных целей развития Российской Федерации на период до 2024 года.

- постановление Правительства Российской Федерации от 29 марта 2019 г. № 377 «Об утверждении государственной программы Российской Федерации «Научно-технологическое развитие Российской Федерации».

В ближайшем будущем ожидается дальнейшая трансформация государственной политики в научно-образовательной сфере. Предлагается для обсуждения единый национальный проект в сфере высшего образования и науки на 20212030 годы - национальный проект «Наука и университеты». В единый нацпроект войдут четыре федеральных проекта: «Интеграция», «Исследовательское лидерство», «Инфраструктура», «Кадры».

В итоге, на примере современного административно-правового регулирования сферы образования и науки представлены новые формы управленческой деятельности и его обновленные методы, неразрывно связанные с сущностью и единством проводимой государством политики.

\section{Библиографический список}

1. Научные основы государственного управления в СССР. М.: Издательство «Наука», 1968. С. 219

2. Там же.

3. Там же.

4. Научные основы государственного управления в СССР. М.: Издательство «Наука», 1968. С. 215.

5. Щукина Т.В. Правовое регулирование программно-целевого подхода в системе государственного управления в условиях стратегического развития Российской Федерации // Вопросы экономики и права. 2018. № 10 (124). С. 8-10

6. Васильев А.И., Прокофьев С.Е. Организация проектного управления в органах государственной власти // Государственное и муниципальное управление. 2016. № 4. С. 46. 
7. Правовое регулирование новых стратегий публичного управления в Российской Федерации: учебник для магистратуры / Т. В. Щукина.-Воронеж: ИПЦ «Научная книга», 2018. С. 131-157.

8. Там же.

9. Там же. 